Journal of Applied Fluid Mechanics, Vol. 15, No. 1, pp. 109-116, 2022.

Available online at www.jafmonline.net, ISSN 1735-3572, EISSN 1735-3645.

https://doi.org/10.47176/jafm.15.01.32826

\title{
Research on Thrust Calibration Technology of Aeroengine Indoor Test Bench
}

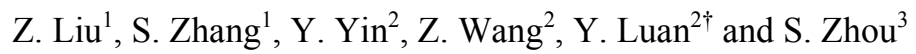 \\ ${ }^{1}$ AECC Shenyang Engine Research Institute, Shenyang, Liaoning, 110015, China \\ ${ }^{2}$ Harbin Engineering University, Harbin, Heilongjiang, 150001, China \\ ${ }^{3}$ China Ship Research and Design Center, Wuhan, Hubei, 430000, China \\ †Corresponding Author Email: shandong-313@163.com
}

(Received March 29, 2021; accepted August 6, 2021)

\begin{abstract}
In order to solve the problem of insufficient thrust measurement accuracy of aeroengine indoor testbed, the thrust calibration experiment technology is studied. Form two aspects of engine static calibration and dynamic calibration, the mechanism of thrust calibration is comprehensively analyzed form the perspective of testbed and engine, and a complete set of operable test specifications is formed. The technical difficulties of engine consistency, inlet temperature deviation and non-standard weather are solved, and the accuracy of thrust transmission process is ensured. The test scheme of indoor test bed calibration is given, and the corresponding ideas and requirements are given according to the test conditions, test bench, calibration engine, test process and result analysis, to ensure the accuracy of calibration results.
\end{abstract}

Keywords: Aeroengine; Indoor testbed; Thrust calibration; Momentum correction; Thrust transfer.

\section{NOMENClATURE}

$\begin{array}{lll}\text { MCM } & \text { Momentum Correction Method } & \mathrm{d} \\ \text { TTM } & \text { Thrust Transmission Method } & \mathrm{V}_{0} \\ \text { AIP } & \text { Air Interface of Pneumatic } & \mathrm{DC}_{60} \\ & & \\ \text { IS } & \text { Idle Speed } & \mathrm{P}^{*}{ }_{\text {av }} \\ \text { MS } & \text { Middle Speed } & \mathrm{q}_{\mathrm{av}} \\ & & \mathrm{F} \\ \text { FAS } & \text { Fully Accelerated State } & \mathrm{n}_{1} \\ \text { T } & \text { the thrust at standard weather condition } & \mathrm{T}_{1} \\ \text { XP } & \text { pressure correction coefficient } & \mathrm{XF} \\ \text { CT } & \text { temperature correction coefficient } & \varphi \\ \text { CH } & \text { humidity correction coefficient } & \theta \\ \text { CC } & \text { inflow condensation correction coefficient } & \theta\end{array}$

\author{
moisture content \\ ambient wind velocity \\ circumferential total pressure \\ distortion index \\ average total pressure of AIP section \\ average dynamic pressure of intake \\ passage outlet \\ thrust transmission \\ engine rotating velocity \\ total intake temperature \\ thrust coefficient \\ relative humidity \\ ambient wind direction angle
}

\section{INTRODUCTION}

The aircraft uses the thrust generated by the aero engine to overcome the resistance and fly (Lian and Wu 2005). Thrust is the most important performance index of the aero engine (Cheng et al. 2019). With the development of high-performance engines, it is more and more important to improve the accuracy of the thrust measurement of the engine on the test bench (Zhang 2014).

Test benches are mainly divided into open-air benches (Liu et al. 2006; Jiao and Lu 2008), indoor test benches, high-altitude test benches (Wu 1995), flying test benches, and other special test benches. Due to different environments and benches, each test bench has deviations in thrust measurement (Chen 2014).

The current research on the thrust of the test bed mainly focuses on error source analysis (Zhang 2016), error control (Lin 2014), calibration methods (Fan et al. 2012; Li et al. 2015), software (Zhao et al. 2016) and hardware design, etc. The sources of thrust measurement errors mainly include sensor measurement errors, errors caused by unreasonable 
force transmission structure, elastic element errors, system eccentricity, and accumulation of errors in the measurement system (Huang et al. 2020). After determining the source of the error, the error can be reduced by improving the test method, adjusting the structure of the bench, and improving the test system (Liu et al. 2019). Or, by calibrating the platform, the accumulated errors of each system can be eliminated to achieve the purpose of measuring true thrust. The impact of the engine's environment on the engine thrust is currently little research.

Aiming at the problem of inconsistent thrust test standards on domestic test rigs (HB/Z311-98), this paper analyzes the main influencing factors of openair benchmark test rigs based on the characteristics of engines with low bypass ratio. The appropriate test conditions are determined by numerical simulation method, and the thrust coefficient of the indoor test bed is obtained through the thrust transmission of the reference platform and the two indoor platforms. This method has guiding significance for the determination of the thrust coefficient of other test benches.

\section{THRUST CALIBRATION METHOD}

The engine thrust provided by the indoor test bench is the actual measured thrust obtained through the bench force measurement system. The measured thrust is corrected by the aerodynamic characteristics of the test bench to become the physical thrust of the engine, and then the converted thrust of the engine is finally obtained by the engine intake pressure conversion and intake temperature correction. The key processes that affect the accuracy of engine thrust include the bench force measurement system, the correction of the aerodynamic characteristics of the test bench, and the correction of the intake air temperature.

The airflow through the indoor air intake system has pressure loss, and there is a relative speed between the airflow and the engine, which cannot satisfy the ground static state. The static pressure changes and frictional resistance of the external flow along the length of the engine will cause the measurement thrust loss. The static pressure drop at the tail nozzle caused by the exhaust system will cause the measured thrust loss.

The dynamic thrust calibration of indoor test bed is mainly divided into momentum correction method (MCM) and thrust transmission method (TTM). The TTM uses the calibrated engine to test between the reference test bench and the calibrated test bench. During the test run, the temperature and the engine state remain exactly the same, ang the engine thrust is equal. According to the known thrust of the benchmark test bed, the thrust correction coefficient of the test bed to be schooled is derived. The thrust correction coefficient of the calibrated test bench is derived based on the known thrust of the reference test bench. The momentum correction method is finally getting the thrust correction coefficient, through sorting out all the additional thrust that should be corrected.
The exactly same conditions of atmospheric humidity, temperature, and pressure required for thrust transmission cannot be achieved in the industry. The accuracy of the results of the momentum correction method depends on the accuracy of the thrust measurement system and the flow field characteristics of the test shop cannot be obtained by measurement, but can only be obtained by similar processing of the measurement results of the key points of the characteristic section. The prerequisites for the application of the thrust transfer method are to have a calibrated engine and a reference test bench. Test departments in the industry generally have the conditions for thrust transmission, and the momentum correction method is generally used under the precondition of not having a benchmark test bench.

\section{TEST BENCH THRUST CALIBRATION TESTS}

\subsection{Aeroengine thrust correction}

The aeroengine thrust is affected by surrounding conditions (GJB722-89), the thrust at standard weather level condition (GB1920-80) should be calculated from thrust at different test conditions as:

$T=T_{c l} \times X P \times C T \times C H \times C C$

Where $C T$ is temperature correction coefficient (GJB378-87), XP is pressure correction coefficient, $\mathrm{CH}$ is humidity correction coefficient (GJB35987), $C C$ is inflow condensation correction coefficient. The performance calculation in the thrust transfer test should use the corrected physical parameter values. The aim of correcting temperature and pressure is to translate the engine performance to that at standard weather level condition. The inflow condensation correction coefficient is set to 1.0 .

\subsubsection{Temperature correction}

As shown in Fig. 1, the thrust coefficient firstly decreases and then rises in the inflow temperature range of $-40 \sim 40^{\circ} \mathrm{C}$. In engineering application, the $\mathrm{CT}$ of $15{ }^{\circ} \mathrm{C}$ temperature is assumed to be 1 . Due to the large intake flow in low temperature conditions, in order to ensure the same pneumatic load in low temperature days and normal temperature weather. Therefore, it is necessary to maintain a small temperature coefficient when the temperature is below zero, and $-2^{\circ} \mathrm{C}$ is an empirical engineering value. In Fig. 1, the thrust changes slightly with inflow temperature in the range of $40 \sim-2^{\circ} \mathrm{C}$, while the CT is shown to decrease with the temperature and then rise sharply again at $-2^{\circ} \mathrm{C}$. So, the inflow temperature has a great impact on the thrust in the range of $-2 \sim 40^{\circ} \mathrm{C}$. With an inflow temperature variation of $-2^{\circ} \mathrm{C}$, the relative change of thrust is $0.05 \%$ in the range of $-40 \sim-2^{\circ} \mathrm{C}, 1.15 \%$ in the range of $-2 \sim 40^{\circ} \mathrm{C}$ and even $4 \%$ just around $40^{\circ} \mathrm{C} . T_{1}$ should be around $15^{\circ} \mathrm{C}$ and the temperature variation should be minor in practical tests. 


\subsubsection{Pressure correction}

The $X P$ is mainly related to local pressure and actual engine inflow pressure. The correlation between pressure correction coefficient and temperature is shown in Fig. 2. The $X P$ reaches 1.0 at $15^{\circ} \mathrm{C}$ and is more than 1.0 as the temperature is lower than $15^{\circ} \mathrm{C}$ and less than 1.0 as temperature higher than $15^{\circ} \mathrm{C}$.

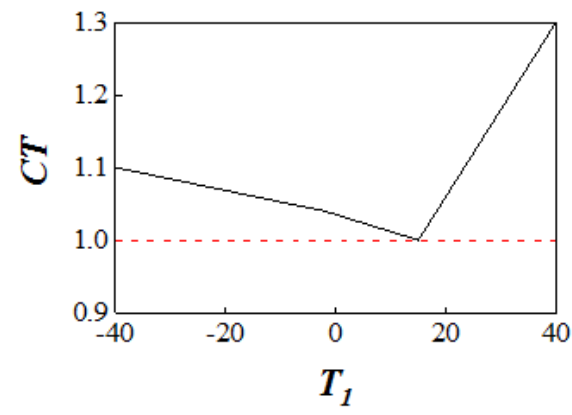

Fig. 1. Temperature correction coefficient at non-standard weather level condition.

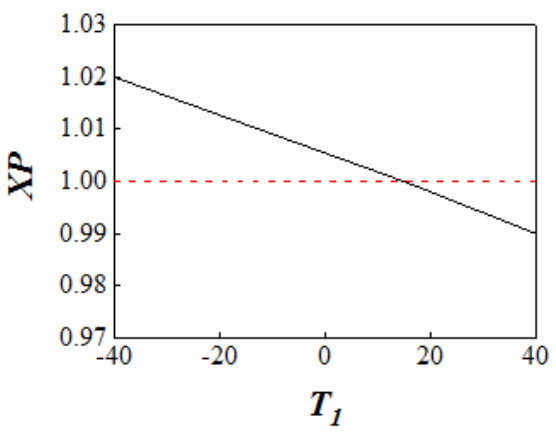

Fig. 2. Pressure correction coefficient at nonstandard weather level condition.

\subsubsection{Humidity correction}

The tests should not be conducted at relatively high humidity. Hence the humidity correlation coefficient $\mathrm{C} \mathrm{CH}$ ) have slight effect on thrust when it is relatively small. The correlation between moisture content $d$ and relative humidity $\varphi$ is as follows.

$d=\frac{0.622 \cdot \phi \cdot P_{S \max }}{P_{0}-\phi P_{S \max }}$

The thrust correction coefficient is proportionate to the humidity, and same linear relationship of humidity correlation coefficient and moisture is presented in Fig. 3. The humidity correlation coefficient is 0 as moisture content is equal to 0 , and it gradually increases with moisture content when moisture content is greater than 0 .

\subsection{The contributing factors of baseline outdoor tests and their control}

Besides the correction of temperature, pressure, humidity and condensation coefficient, the tests on

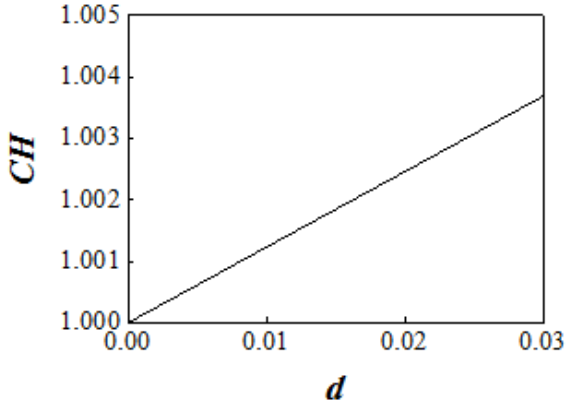

Fig. 3. Humidity correction coefficient at nonstandard weather level condition.

the aeroengine baseline outdoor test bench are also affected by wind speed and wind direction.

\subsubsection{The effect of wind velocity}

When the inflow velocity is set to $0 \mathrm{~m} / \mathrm{s}$, the engine is surrounded in a totally static ambience, shown in Fig. 4. The intake system absorbs air from all the directions, and the absorbed air separates at the outlet section of intake system. One part of air flows to the engine inlet under the suction of intake system, the other part of air flows to the nozzle under the ejecting effect of engine outflow jet and is absorbed by the engine exhaust.

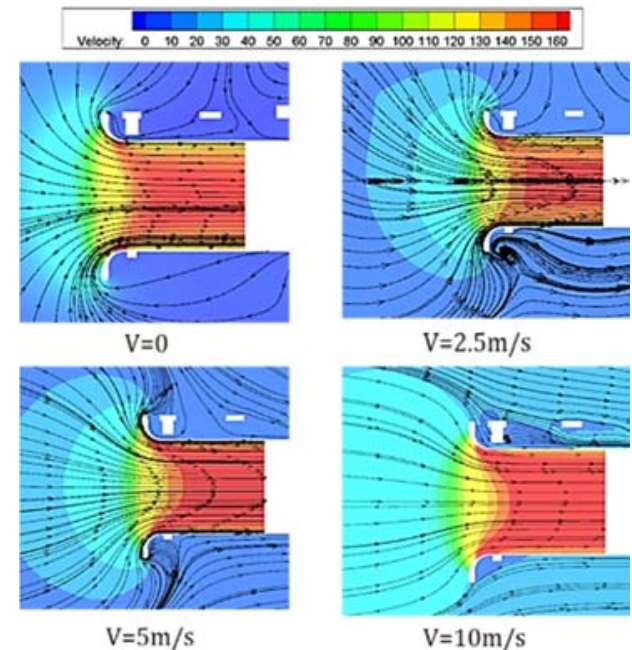

Fig. 4. Inflow streamlines of the baseline testbed intake passage.

Due to the presence of the earth ground and the ejecting effect of the overall intake and exhaust system, the air closed to the ground has the same velocity direction with the engine inflow. The air beneath the engine is absorbed by the intake system and flow separation takes place near the ground. The inflow becomes increasingly uniform with the growth of ambient wind velocity. Obvious entrainment phenomenon can be observed around the inlet of the intake passage as the ambient wind velocity is $2.5 \mathrm{~m} / \mathrm{s}$. The velocity of the air around the 
engine is relatively low as the ambient wind velocity is low, hence great entrainment of surrounded air occurs to match the inflow mass rate of the engine and noticeable secondary flow region is formed. And there is axial pressure gradient at the intake passage lip, these phenomena introduce additional resistance to the intake passage. With the increase of ambient wind velocity, the backflow vortexes gradually disappear but the entrainment still exists.

In Fig. 5, the local low-pressure high-velocity region at the root of intake passage lip disappears when the wind velocity reaches $5 \mathrm{~m} / \mathrm{s}$. The reason is that the suction of engine intake system on the air reduces with the increase of inflow velocity and the inflow would not be compressed at the lip root even if the passage convergence exists. The flow field in the intake system becomes uniform when the wind velocity reaches $10 \mathrm{~m} / \mathrm{s}$, and there is no obvious recirculation and entrainment phenomena near the

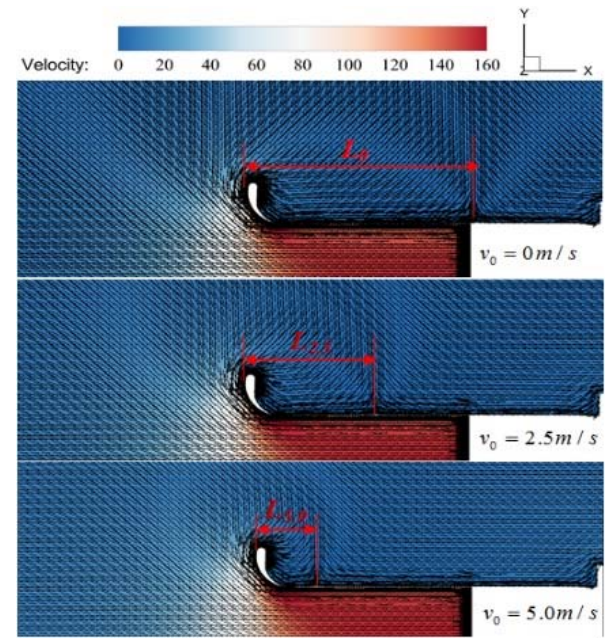

Fig. 5. Velocity vectors under different wind velocity conditions.

lip root. Meanwhile, the pattern of intake flow field of the outdoor engine testbed is similar to that of indoor engine test bench.

It is shown in Fig. 6 that the relative difference of the physical quantities on air interface of pneumatic (AIP) section increases with the ambient wind velocity. When the ambient wind velocity is lower than $5 \mathrm{~m} / \mathrm{s}$, the relative physical quantities is all smaller than 3\%. But the relative physical quantities grow faster with the wind velocity as it is higher than $5 \mathrm{~m} / \mathrm{s}$. Therefore, the engine tests should be carried out when the ambient wind velocity is lower than $5 \mathrm{~m} / \mathrm{s}$, which can effectively reduce the effect of environment on tests.

\subsubsection{The effect of wind direction}

As shown in Fig. 7, The wind direction angle $\theta$ is defined as the angle between the wind direction and the axis of engine inlet. $\theta=0^{\circ}$ means that the air horizontally flows into the engine inlet. When the wind velocity is euqal to $5 \mathrm{~m} / \mathrm{s}$, the engine wake gradually deviates with the wind direction angle increasing. However, the wind direction angle has little influence on the engine intake as the wind velocity is relatively low.



Fig. 6. Variation of the physical quantities on AIP section with wind velocity.

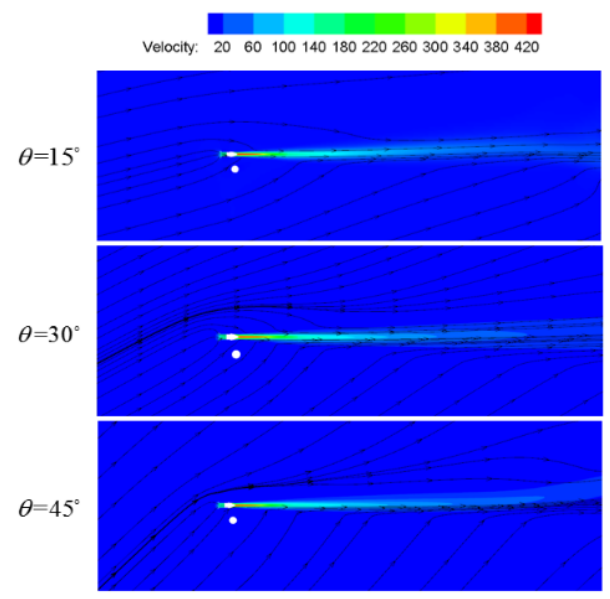

Fig. 7. Velocity contour and streamlines under different wind directions.

It can be observed from the velocity contour and streamlines of the engine intake passage in Fig. 8, that the velocity field outside the engine intake passage is nonuniform but the nonuniformity disappears just after the flow getting into the intake passage, and the flow velocity direction in the intake passage is identical to horizonal wind. The velocity gradient field outside the intake passage outlet deviates towards the inflow direction. It can be concluded that the ambient wind direction only has impact on the flow field before entering the engine intake in the range of $0-60^{\circ}$ as the ambient wind velocity is $2.5 \mathrm{~m} / \mathrm{s}$.

Figure 9 shows that the total pressure contours on AIP section under the horizonal wind direction. The total pressure distribution of the AIP section of the air inlet at different wind direction angles, there is no obvious difference between the downwind and the cloud diagram with a wind direction angle of $60^{\circ}$. The performance characteristics are that the total 


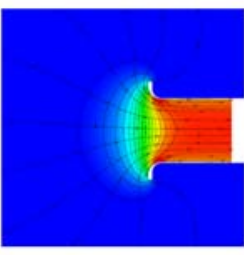

$0-0$

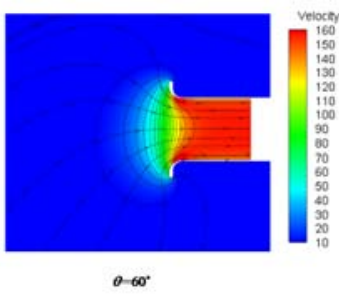

Fig. 8. Velocity contour and streamlines of intake passage under different wind directions.
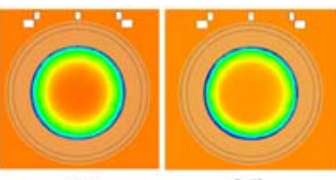

$\theta$ Q QI

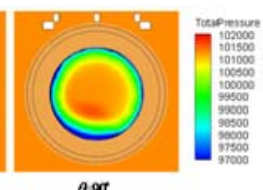

$\theta 90$ 9. Total pressure contour of AIP
under different wind directions.

pressure in the central area of the radial distribution is large, and the total pressure near the wall of the engine inlet is reduced due to the effect of the viscosity loss, but the total pressure distribution in the circumferential direction is uniform. The total pressure distribution on AIP section under $90^{\circ}$ wind direction is different, since lateral airflow decelerates and diffuses in the intake passage lip, part of the airflow is separated near the surface of the intake passage and the low total pressure region in the lower left of AIP section is enlarged. The inlet distortion under $90^{\circ}$ wind direction is the greatest, which demonstrates that the ambient wind direction can affect the total pressure distribution on AIP section and further influence the intake characteristics.

The velocity and pressure variation of AIP section under different wind directions with the wind velocity fixed at $5 \mathrm{~m} / \mathrm{s}$ is presented in Fig. 10 . The physical quantities relative to 0 wind direction angle situation all increase with wind direction angle. The variation curves of central pressure and average pressure overlap. The influence of wind direction angle on the central velocity is the greatest, and the relative average velocity is around $5 \%$ as the wind direction angle is $180^{\circ}$.

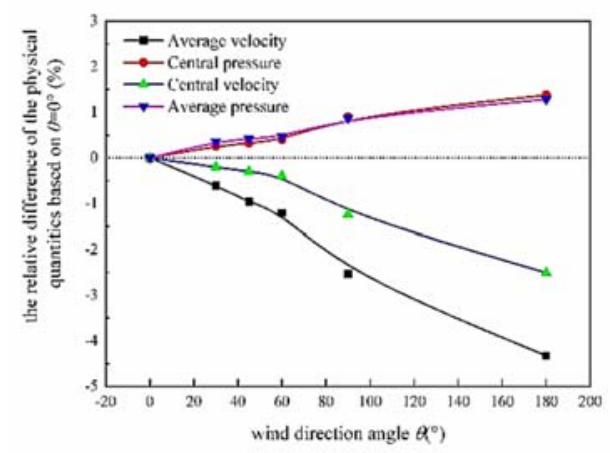

Fig. 10. Variation of the physical quantities on AIP section with wind direction.
In order to quantitatively measure the degree of airflow distortion, the circumferential total pressure distortion index $D C_{60}$ is introduced, which is defined as:

$D C_{60}=\frac{P_{a v}^{*}-\bar{P}_{\min 60^{\circ}}^{*}}{q_{a v}}$

Where $P_{a v}^{*}$ is the average total pressure of AIP section, $q_{a v}$ is the average dynamic pressure of intake passage outlet, $\bar{P}_{\min }^{*} 60^{\circ}$ is the minimum average total pressure within $60^{\circ}$.

In Fig. 11, the conditions of outdoor baseline test points were shown. The circumferential total pressure distortion index $D C_{60}$ should be less than 0.0025 to ensure the flow stability in the intake passage. When $D C_{60}$ exceeds 0.0025 , obvious inlet distortion occurs in the intake passage, which is not suitable for baseline engine tests. $D C_{60}$ under different inflow conditions is obtained through numerical simulation in order to obtain the tolerance boundary of wind direction angle and wind velocity to engine inlet distortion.

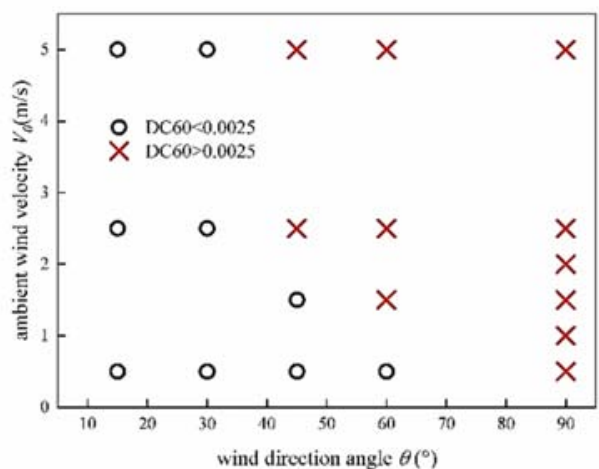

Fig. 11. Conditions of outdoor baseline test points.

The numerical simulation study indicates that as the ambient wind velocity is less than $5 \mathrm{~m} / \mathrm{s}$ and the wind direction angle is within $\pm 60^{\circ}$, the wind velocity and direction have little influence on the engine intake, and the test points within this range can ensure that there is no drastic change of parameters or distortion in the baseline tests.

\subsection{Test process study}

In the process of engine thrust transmission, power is not separated, the combat state is adopted, and the state of the control system is consistent. Engine performance degradation is not allowed, and the thrust should be recalibrated and verified after completion of calibration tests. The thrust system and measuring system of the testbed should be checked before the thrust calibration test to prevent large errors.

Test bench, engine and test conditions should be confirmed before testing as shown Fig. 12. In order to ensure that the baseline test process is consistent with the calibration test process, in addition to follow 
the conventional test process, it should be noted that the same type of intake device is used during the engine installation. Measurement location, number, layout of temperature and pressure parameter and testing equipment should be the same in pneumatic flow channel. The test procedure should be the same. The test procedure is as follows Table 1 and Fig. 13. IS is idle speed, MS is middle state, FAS is fully accelerated state. The front part of the procedure is the warm-up procedure, in order to make the engine reach the ideal working state, and the back part is the performance register procedure, in order to enroll the engine performance.

Table 1 Performance register procedure

\begin{tabular}{|c|c|c|c|}
\hline $\begin{array}{c}\text { Orde } \\
\mathrm{r}\end{array}$ & Status & $\begin{array}{l}\text { Operatin } \\
\text { g time } \\
(\mathrm{min})\end{array}$ & $\begin{array}{c}\text { Operating } \\
\text { instruction }\end{array}$ \\
\hline 1 & Start & - & $\begin{array}{c}\text { Combat } \\
\text { state }\end{array}$ \\
\hline 2 & IS & 3 & - \\
\hline 3 & $\mathrm{n} 2=85 \%$ & 3 & - \\
\hline 4 & $\mathrm{n} 2=90 \%$ & 3 & - \\
\hline 5 & $\mathrm{n} 2=95 \%$ & 3 & - \\
\hline 6 & $\begin{array}{c}\text { MS(n2 }=100 \\
\%)\end{array}$ & 3 & - \\
\hline 7 & FAS & 2 & - \\
\hline 8 & IS & 3 & $\begin{array}{c}\text { Performanc } \\
\text { e register }\end{array}$ \\
\hline 9 & $\mathrm{n} 2=85 \%$ & 3 & $\begin{array}{c}\text { Performanc } \\
\text { e register }\end{array}$ \\
\hline 10 & $\mathrm{n} 2=88 \%$ & 3 & $\begin{array}{c}\text { Performanc } \\
\text { e register }\end{array}$ \\
\hline 11 & $\mathrm{n} 2=90 \%$ & 3 & $\begin{array}{c}\text { Performanc } \\
\text { e register }\end{array}$ \\
\hline 12 & $\mathrm{n} 2=92 \%$ & 5 & $\begin{array}{c}\text { Performanc } \\
\text { e register }\end{array}$ \\
\hline 13 & $\mathrm{n} 2=94 \%$ & 5 & $\begin{array}{c}\text { Performanc } \\
\text { e register }\end{array}$ \\
\hline 14 & $\mathrm{n} 2=95 \%$ & 5 & $\begin{array}{l}\text { Performanc } \\
\text { e register }\end{array}$ \\
\hline 15 & $\mathrm{n} 2=97 \%$ & 5 & $\begin{array}{c}\text { Performanc } \\
\text { e register }\end{array}$ \\
\hline 16 & $\mathrm{n} 2=99 \%$ & 5 & $\begin{array}{l}\text { Performanc } \\
\text { e register }\end{array}$ \\
\hline 17 & MS & 2 & $\begin{array}{c}\text { Performanc } \\
\text { e register }\end{array}$ \\
\hline 18 & FAS & 2 & $\begin{array}{c}\text { Performanc } \\
\text { e register }\end{array}$ \\
\hline 19 & $\mathrm{n} 2=85 \%$ & 3 & - \\
\hline 20 & IS & 5 & - \\
\hline 21 & Shut down & - & - \\
\hline
\end{tabular}

\subsection{Results and discussion}

After the performance register procedure, the thrust transmission $(F)$ is carried out between the indoor test bench 1 and indoor test bench 2, as shown in Fig. 14. From the perspective of engine control, the thrust variation of the three test benches with rotating velocity $\left(n_{l}\right)$ is completely consistent with each other, which indicates the consistency of the engine state. The consistency of the engine state indicates the same thrust.

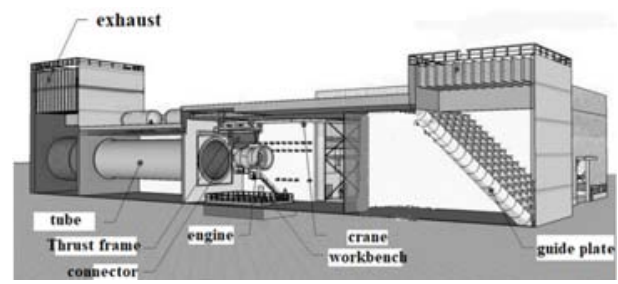

Fig. 12. Typical indoor testbed structure.

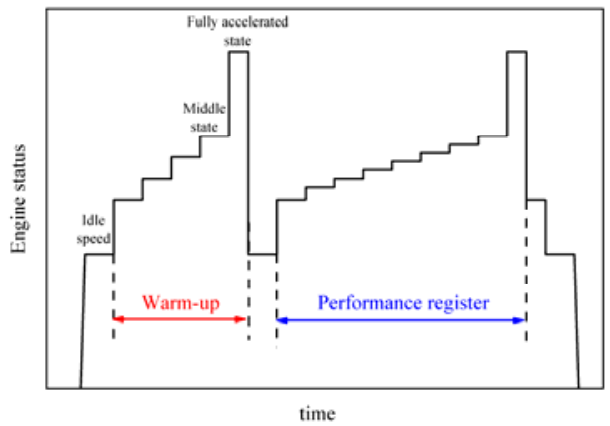

Fig. 13. Engine test procedure.

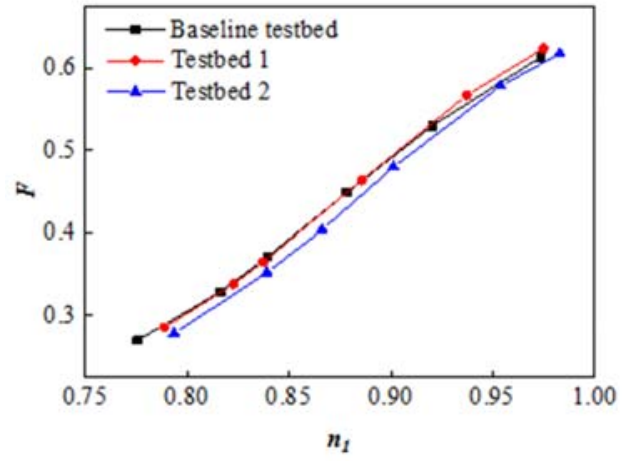

Fig. 14. Comparison of all-status thrust transmission.

The engine control parameters are related to the total intake temperature $T_{l}$ and the throttle lever angle. The throttle lever angle is easy to control. The consistency of the engine state finally attributes to the consistency of the total intake temperature $T_{l}$. The temperature difference among the three test beds in thrust transfer test was controlled within $0.8^{\circ} \mathrm{C}$, and $T_{l}$ did not fluctuate significantly in the test process, which ensures the consistency of the key parameter, inlet temperature $T_{l}$. At this time, the thrust of the three test beds was consistent, and the 
thrust coefficients of the three test beds were obtained by comparing the thrust with that of the baseline testbed. In Fig. 15, the thrust of the baseline testbed is 0.614 , the thrust of testbed 1 is 0.599 , and the thrust of testbed 2 is 0.596 . The maximum difference among the three testbeds is 0.018 , and the difference value is $2.89 \%$ of the thrust of the baseline testbed. The thrust of the baseline testbed is greater than that of the two testbeds to be calibrated, which verifies that the actually measured thrust decreases due to the existence of various resistances during the indoor test.

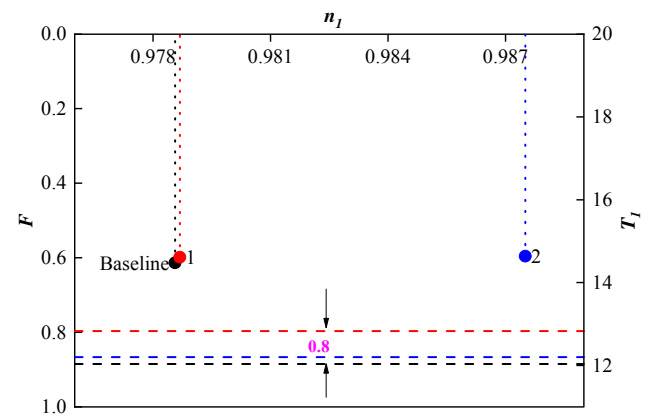

Fig. 15. Results of thrust transmission $(F)$.

The thrust coefficient XF is defined as the ratio of the thrust of the baseline test bench to the thrust of the test bench to be calibrated. The real thrust is obtained by multiplying the thrust measured from the tests with XF. After the thrust calibration, the thrust coefficient of the baseline testbed is set as 1 , and $\mathrm{XF}$ of test benches 1 and 2 are 1.034 and 1.039 respectively. The measured thrust of the indoor test bench is less than that of the outdoor baseline test bench because of the intake impulse, windward resistance and nozzle negative pressure of the engine in the indoor test bench, of which the intake impulse accounts for about $70 \%$. The true thrust of the indoor test bench should be the sum of the measured thrust and the thrust corrected by various resistances.

The thrust was recalibrated after the completion of thrust transfer test, and the results were shown in Fig. 16. The thrust variation is consistent with the rotational speed $\left(n_{1}\right)$, indicating that there is no performance degradation of the engine, and the consistency of the engine thrust is guaranteed.

Through the means of thrust transmission, the thrust calibration of the indoor test bench can be carried out, and the thrust coefficient of the test bench can be given. The method is also applicable to high altitude test bench, flight test bench and special test bench, and has the value of popularizing.

\section{Conclusions}

In order to solve the problem that the engine thrust is not consistent, and the standard is not uniform between different testbeds, the engine testbed thrust transfer technology research is conducted, comprehensivee analysis of the thrust calibration mechanism is done. The paper also analyzes the

Table 2 Thrust coefficient (XF)

\begin{tabular}{|c|c|c|c|}
\hline $\begin{array}{c}\text { Test } \\
\text { bench }\end{array}$ & $\begin{array}{c}\text { Baseline } \\
\text { test bench }\end{array}$ & $\begin{array}{c}\text { Test } \\
\text { bench 1 }\end{array}$ & $\begin{array}{c}\text { Test } \\
\text { bench 1 }\end{array}$ \\
\hline XF & 1 & 1.034 & 1.039 \\
\hline
\end{tabular}

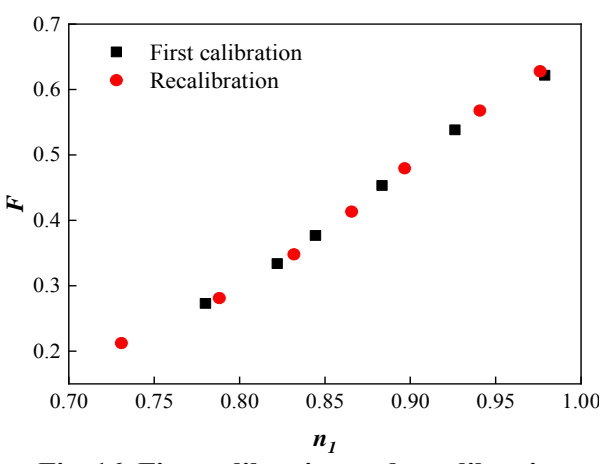

Fig. 16. First calibration and recalibration.

influence factors of the outdoor baseline engine tests. The thrust correction considering factors such as temperature, pressure and humidity is carried out, and the test conditions of engine thrust calibration is obtained. The thrust coefficients of different testbeds are obtained through the reasonable test process control:

a) The definition of thrust transfer technology is discussed, which refers to using completely identical engines to test different test beds at the same intake temperature. The thrust is equal after mathematical conversion, and the thrust coefficient of the testbed to be calibrated is given.

b) Given the correction coefficients of temperature, pressure, humidity and intake condensation coefficient that affecting the engine thrust, the thrust at standard weather level condition can be obtained after conversion.

c) The influencing factors of outdoor baseline testbed thrust performance register test are analyzed, and wind speed and wind direction are the main factors. When the wind speed is low, the intake passage has obvious entrainment to the surrounding air, and there are backflow vortexes. With the increase of the wind speed, the suction effect of the intake passage decreases, the backflow vortexes reduce, and the flow field is more similar to the indoor test bed. As the wind speed increases, the pressure and wind speed of the aerodynamic section of the intake passage are both increasing compared with their values at 0 wind speed, and the growth rate is significant when the wind speed is greater than $5 \mathrm{~m} / \mathrm{s}$.

d) As the wind direction angle increases, the engine wake deviation becomes more and more obvious. The uniformity of streamlines and pressure gradient in the intake passage, however, will disappear after the air flow entering the inlet. The larger the inlet wind direction angle is, the more obvious the change 
of total pressure distribution on the aerodynamic section of the intake passage is, and the change of pressure and wind speed also increases compared with the $0^{\circ}$ wind direction angle situation, and the change gets even faster in the wind direction angle range of $\pm 60^{\circ}$.

e) The outdoor testbed calibration should select the ambience that wind speed is below $5 \mathrm{~m} / \mathrm{s}$ and wind direction angle is within $\pm 60^{\circ}$, which is the most suitable.

f) After the baseline tests on the outdoor testbeds, the baseline tests were carried out on the two indoor testbeds, and the temperature difference was controlled within $0.8{ }^{\circ} \mathrm{C}$. The thrust coefficients of the two indoor testbeds were obtained after mathematical conversion and thrust comparison, which were 0.6135 and 0.5986 respectively. The thrust transfer technology of engine testbed has universality in domestic testbeds, and can be applied to high altitude testbeds and flight testbeds.

\section{ACKNOWLEDGEMENTS}

The Chief Editor of JAFM would like to thank all authors for their contributions and the submission of their papers.

\section{REFERENCES}

Aviation Industry Standard of the People's Republic of China. HB/Z311-98 Flight thrust determination guide. 1998 .

Chen, B. (2014). Test Techniques and Methods for Aeronautical Turbofan Engine. Shanghai Jiao Tong University, Shanghai, China, 200-249.

Cheng, R., Z. Zhang and Z. Chen (2019). Technical characteristics and implementation of the fourth-generation jet fighter engines. Acta Aeronautica et Astronautica Sinica 40(3), 022698.

Fan, J., G. Wang, Z. Jingand D. Zhao (2012). Trust Measurement and Calibration of Turbofan Engine Test Cell. Metrology and Measurement Technology 35(5), 1-4.

Huang, C., W. Jin, J. Qu, B. Xue and Y. Cao (2020). Measurement of Thrust of Aero Engine's Indoor Test Bench and its Traceability System. Metrology \& Measurement Technology 40(3), 16-20.

Jiao, T. and B. Lu (2008). Technical Demonstration of Constructing Open-air Test Bed for Large
Transport Aircraft Engines. Gas Turbine Experiment and Research 21(1), 1-9.

Li, L., Y. Ye and C. Ma (2015). Thrust Calibration System for Aeroengine Testing Bench. Engineering and Test 55(2), 89-91.

Lian, Y. and H. Wu (2005). Aero-engine Principle. Northwestern Polytechnical University, Xi'an, China, 13-19.

Lin, S. (2014). Trust Analysis of Thrust System for Aeroengine Test Cell. Measurement and Control Technology 33, 84-86.

Liu, T., W. Xue and B. Ren (2019). Calibration and Loading Method of Thrust Measurement System for Turbojet and Turbofan Engine Test Cell. In Aviation Equipment Service Support and Maintenance Forum and Annual Meeting of China Aviation Industry Technical Equipment Engineering Association, China, 548-551.

Liu, Z., X. Guo and L. Wang (2006). Requirement of Outdoor Test Bed on the Location Level. Gas Turbine Experiment and Research 19(1), 6-10.

National Military Standards of the People's Republic of China. GJB722-89 Specification for modification of turbofan engine test performance. 1989.

National Military Standards of the People's Republic of China. GJB378-87 Temperature Correction Specification for Turbojet and Turbofan Engine Performance. 1987.

National Military Standards of the People's Republic of China. GJB359-87 Humidity correction specification for turbofan engine performance. 1987.

PRC National Standard. GB1920-80 Standard atmosphere (the part below 30km). 1987.

Wu, D. (1995). Application Prospect of aeroengine Altitude Platform and Flight Platform in China. Gas Turbine Experiment and Research 02, 1-5.

Zhang, A. (2014). System design of a new aeroengine enclosed test cell. Ph. D. thesis, Hunan University, Changsha, China.

Zhang, Y. (2016). Principle Errors Analysis of Thrust Measurement Test Bench System for Aeroengine. Aeroengine 42(4), 76-80.

Zhao, C., W. Zhang and Y. Cao (2016). Software System Design of Aeroengine Thrust Bench Calibration. Measurement and Control Technology 35, 480-483. 